\title{
Relationship between Type 2 Diabetes Mellitus and Alcohol Consumption among Young Adults in Mangalore: A Cross Sectional Study
}

\author{
Tobin Joseph ${ }^{1}$, Saumya P Jose ${ }^{2}$ \\ ${ }^{1}$ Professor, Head of the Department, Indira College of Nursing, Falnir, Mangalore, Karnataka - 575002 \\ ${ }^{2}$ Associate Professor, Vidyarathna College of Nursing, Uduppi, Mangalore, Karnataka - 576101
}

Corresponding Author: Tobin Joseph

\begin{abstract}
Diabetes mellitus is one of the most common comorbid illnesses seen in adults and elderly individual. Its prevalence rate is increasing globally and in India. $7.1 \%$ of the total population is affected with diabetes. The present study is a community based cross sectional study to investigate the relationship between alcohol consumption and diabetes incidence among young adults. 120 participants were recruited through purposive sampling. Fasting blood sugar and post prandial blood sugar level were taken to identify the diabetic profile. The data were collected and analyzed by using descriptive statistics and results showed that there is a strong association exit between these parameters.
\end{abstract}

Keywords: Type 2 Diabetes Mellitus, Alcohol Consumption, Young Adult, Mangalore

\section{INTRODUCTION}

Diabetes has become a fast growing serious chronic health issue in the world, with the number of people living with diabetes rising significantly over the last few years. It is one of the most common chronic disease in India so far and India also called as diabetes capital due to highest cases found in the country. ${ }^{1,2}$ There are now reported to be 422 million adult diabetics (1 in 11) internationally, the majority having type 2. According to the World Health Organization (WHO), the biggest increase is among low and middle income countries. There are many short-term and long-term complications that arise from poorly managed/controlled diabetes. Short-term Complications includes Hypoglycemia, Diabetic ketoacidosis (DKA), Hyperosmolar hyperglycemic state and Long-term Complications includes eyes (retinopathy), Kidneys (nephropathy), Nerves and feet (neuropathy) and Heart (cardiovascular disease). Such complications have dire consequences for a person's health and well-being, as well as a negative effect upon the economies of nations. ${ }^{3,4,5}$ Poorly controlled diabetes can lead to serious health complications, which results in other specialist areas needing to become involved. This means more pressure upon resources and a greater financial burden being placed upon the health system. ${ }^{6,7}$ There are various modifiable and non modifiable risk factors for diabetes. Life style is one of the commonly involved risk factors for diabetes among the young adults. Furthermore there are also evidence on the strong relationship between alcohol consumption and diabetes. ${ }^{8}$ Most of the review article suggests that there is a strong correlation exit between diabetes and alcohol consumption. However clinical and experimental studies are less. This particular study intended to collect the relationship between alcohol consumption and incidence of diabetes mellitus among the young adults. 


\section{METHODOLOGY}

\section{Objectives}

To estimate the prevalence of prediabetic and diabetic Mellitus among the young adults in the rural and urban areas of Mangaluru

$\square \quad$ To identify the correlation of diabetes and alcohol consumption among the young adults

Study design: cross sectional study

Study duration: 2019 February - 2019 may (4 months)

Sampling method: Selected companies in Mangaluru were chosen by simple random sampling and from each company through purposive sampling participants were selected.

\section{Inclusion criteria}

Age - 18 to 35

Gender - male and female

Subjects who are willing to participate in the study.

Exclusion criteria: Subjects who are not willing to participate in the study.

\section{DATA ANALYSIS AND RESULTS}

The obtained data was evaluated using SPSS software version 16.0.

$\square \quad$ The demographic details age and gender were analyzed by using Descriptive statistics.

$\square$ The data was normally distributed so mean and standard deviation was used for demographic data.

Participants: young adults who are willing to participate in the study in the age group 18- 35 years
Procedure: An informed consent was taken from the participants before preceding the study.

Procedure: The required components of assessment including age gender FBS, PPBS were documented in the data collection sheet. The purpose of the study and the procedure was explained to the participants and an informed consent form was obtained before the commencement of the study from each participant. The participants were asked to remain fasting for at least eight hours or the next day morning for assessing the fasting blood sugar, and postprandial blood sugar estimation was carried out two hours after the meal. Glucometer (Accu-Chek Instant) was used to test the blood sugar level. A questionnaire has been prepared for taking the demographic details and alcohol consumption. After the report, the diabetic people were advised to consult a doctor for treatment and pre-diabetic people were given instructions to maintain adequate physical activity and modify dietary habits and also advised to repeat the test once every three months

Table 1
\begin{tabular}{|c|c|c|c|}
\hline & & Frequency & \% \\
\hline Gender & Male & 78 & 65 \\
\hline \multicolumn{3}{|c|}{ Table 2 } \\
\hline Alcohol consumption & Yes & 72 & 35 \\
\hline \multicolumn{3}{|c|}{ Mean } & 63.3 \\
\hline & No & 44 & 36.7 \\
\hline \multicolumn{3}{|c|}{ Teale } & S.D. \\
\hline Age & 27.38 & 5.27 \\
\hline FBS & 96.78 & 17.07 \\
\hline PPBS & 116.44 & 17.01 \\
\hline
\end{tabular}

Table 3: Incidence of diabetes

\begin{tabular}{|l|l|c|c|}
\hline & & Frequency & \% \\
\hline FBS & $70-100$ (Normal) & 87 & 72.5 \\
\hline & $100-125$ (Pre diabetes) & 26 & 21.7 \\
\hline & $>126$ (Diabetes) & 7 & 5.8 \\
\hline PPBS & $<120$ (Normal) & 89 & 74.2 \\
\hline & $120-140$ (Pre diabetes) & 22 & 18.3 \\
\hline & $>140$ (Diabetes) & 9 & 7.5 \\
\hline
\end{tabular}

Table 4: Association between gender, Alcohol consumption and FBS

\begin{tabular}{|c|c|c|c|c|c|c|c|c|c|}
\hline & & FBS & & & & & & Likelihood Ratio & p value \\
\hline & & $\begin{array}{c}\text { 70-100 } \\
\text { (Normal) }\end{array}$ & & $\begin{array}{c}100-125 \\
\text { (Pre diabetes) }\end{array}$ & & $\begin{array}{c}>126 \\
\text { (Diabetes) } \\
\end{array}$ & & & \\
\hline & & $\mathrm{n}$ & $\%$ & $\mathrm{n}$ & $\%$ & $\mathrm{n}$ & $\%$ & & \\
\hline \multirow[t]{2}{*}{ Gender } & Male & 58 & 66.67 & 16 & 61.54 & 4 & 57.14 & 0.427 & 0.808 \\
\hline & Female & 29 & 33.33 & 10 & 38.46 & 3 & 42.86 & & \\
\hline \multirow[t]{2}{*}{ Alcohol consumption } & Yes & 51 & 58.62 & 19 & 73.08 & 6 & 85.71 & 3.678 & 0.159 \\
\hline & No & 36 & 41.38 & 7 & 26.92 & 1 & 14.29 & & \\
\hline
\end{tabular}


Tobin Joseph et.al. Relationship between type 2 diabetes mellitus and alcohol consumption among young adults in Mangalore: a cross sectional study

The Likelihood Ratio test was used to find the Association between gender, Alcohol consumption and FBS. There was no association $(\mathrm{p}>0.05)$ between gender, Alcohol consumption and FBS.

Table 5: Association between gender, Alcohol consumption and PPBS

\begin{tabular}{|c|c|c|c|c|c|c|c|c|c|}
\hline & & PPBS & & 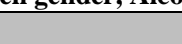 & & & & Chi square & p value \\
\hline & & $\begin{array}{c}<120 \\
\text { (Normal) }\end{array}$ & & $\begin{array}{c}120-140 \\
\text { (Pre diabetes) }\end{array}$ & & $\begin{array}{c}>140 \\
\text { (Diabetes) }\end{array}$ & & & \\
\hline & & $\mathbf{n}$ & $\%$ & n & $\%$ & $\mathrm{n}$ & $\%$ & & \\
\hline \multirow[t]{2}{*}{ Gender } & Male & 58 & 65.17 & 13 & 59.09 & 7 & 77.78 & 0.985 & 0.611 \\
\hline & Female & 31 & 34.83 & 9 & 40.91 & 2 & 22.22 & & \\
\hline \multirow[t]{2}{*}{ Alcohol consumption } & Yes & 49 & 55.06 & 19 & 86.36 & 8 & 88.89 & 10.182 & $0.006^{*}$ \\
\hline & No & 40 & 44.94 & 3 & 13.64 & 1 & 11.11 & & \\
\hline
\end{tabular}

The Chi square test was used to find the Association between gender, Alcohol consumption and PPBS. There was an association $(\mathrm{p}<0.05)$ between alcohol consumption and PPBS.

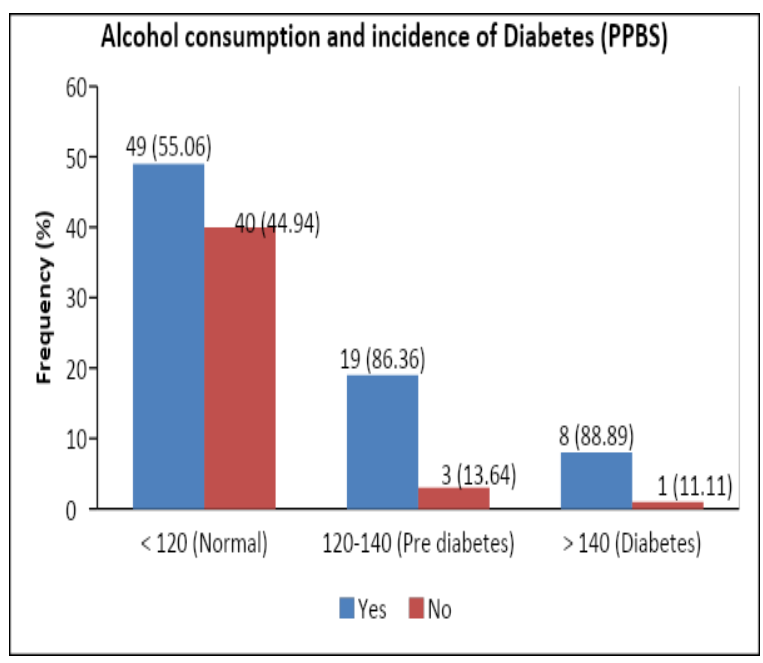

\section{DISCUSSION}

Nowadays diabetes mellitus is becoming a major health care challenge for the country. More than 7.1 percentage of the Indian population is affected by diabetes. ${ }^{3}$ The findings of the present study revealed that there is a strong correlation exist between alcohol consumption and diabetes incidence. Approximately $88.8 \%$ percentage of the individual who are diagnosed diabetes consumes alcohol. The post prandial glucose sugar also high in alcoholics. The findings of the study can be used in clinical practice and decision making skill by reducing the intake of alcohol, the health carer professionals can instruct the patient to reduce the intake of alcohol. So that a homeostatic environment can be maintained as well as liver function can be optimized and it won't interfere the function of pancreas also. Alcohol consumption causes increased carbohydrate intake this causes rise in blood sugar. This excess energy also stores in the form of fat, so the person may get fatty liver. The liver is a major metabolic organ and it mediated many enzymatic reactions. Liver stores the excess glucose in the form of glycogen. When a person consume alcohol liver will try to eliminate the toxic product instead of regulating the glucose metabolism and thus the function gets impaired..$^{9,10,11}$ Prevention as well as delaying the diabetic-associated complications can be achieved by delivering adequate awareness programs and patient education on the importance of physical activity and modifying the dietary intake. Similar to diabetes prevalence estimation the prevalence of pre-diabetic is also important so that with adequate physical activity and lifestyle changes the chances of getting diabetic can be minimized. There have been many population-based epidemiological cross-sectional studies carried out in various parts of the country to find out the prevalence of diabetes. These studies reported that there is a higher prevalence among the male population compared to females. ${ }^{12,13,14}$ Even though genetic predisposition and familial inheritance play an important role, the sedentary lifestyle and food habits are the major contributors.

\section{Acknowledgement: None}

Conflict of Interest: None declared 
Tobin Joseph et.al. Relationship between type 2 diabetes mellitus and alcohol consumption among young adults in Mangalore: a cross sectional study

\section{Source of Funding: None}

\section{Ethical Approval: Approved}

\section{REFERENCES}

1. The Diabetic foot-NHSRC. http://qi.nhsrcindia.org/sites/default/files/Th e Diabetic foot_0.pdf. Accessed May 21, 2021.

2. Ralston S, Penman ID, Strachan MWJ, Hobson RP. Davidsons Principles and Practice of Medicine. Edinburgh: Elsevier; 2018.

3. Shenoy KR, Shenoy A. Manipal Manual of Surgery. New Delhi: CBS Publishers \& Distributors, Pvt Ltd; 2020.

4. Abbas ZG. Low-Cost Management of Diabetic Foot. Diabetic Foot Ulcer. 2020: 221-232. doi:10.1007/978-981-15-76393_14

5. Bhat S. SRBs Manual of Surgery. New Delhi: Jaypee Brothers; 2019.

6. Anette P, Krishna KK, Panayappan L, Leo M. Diabetic foot infection and its management: A review. GSC Biological and Pharmaceutical Sciences. 2018;4(1):19-24. doi:10.30574/gscbps.2018.4.1.0041

7. Wylie-Rosett J. Assessment of documented foot examinations for patients with diabetes in inner-city primary care clinics. Archives of Family Medicine. 1995;4(1):46-50. doi:10.1001/ archfami.4.1.46

8. Greenfield JR, Samaras K, Hayward CS, Chisholm DJ, Campbell LV. Beneficial postprandial effect of a small amount of alcohol on diabetes and cardiovascular risk factors: modification by insulin resistance.
The Journal of Clinical Endocrinology \& Metabolism. 2005 Feb 1;90(2):661-72.

9. McDonald J. Alcohol and diabetes. Diabetes Care. 1980 Sep 1;3(5):629-37.

10. O'Brien KE, Chandramohan V, Nelson DA, Fischer JR, Stevens G, Poremba JA. Effect of a physician-directed educational campaign on performance of proper diabetic foot exams in an outpatient setting. Journal of General Internal Medicine. 2003;18 (4):258-265.doi:10.1046/j.1525-1497.2003. 10662.x

11. van de Wiel A. Diabetes mellitus and alcohol. Diabetes/metabolism research and reviews. 2004 Jul;20(4):263-

12. Polsky S, Akturk HK. Alcohol consumption, diabetes risk, and cardiovascular disease within diabetes. Current diabetes reports. 2017 Dec;17 (12): 1-2.

13. Editor(s): Ziemba, Statira K. MA, RNC Medical-Surgical Nursing: Clinical Management for Continuity of Care, American Journal of Nursing: February 1998 - Volume 98 - Issue 2 - p 16H

14. Collazo-Clavell ML. Lipid Disorders and Diabetes Mellitus. Mayo Clinic Internal Medicine Board Review. 2013:420-431. doi:10.1093/med/9780199948949.003.0028

How to cite this article: Joseph T, Jose SP. Relationship between type 2 diabetes mellitus and alcohol consumption among young adults in Mangalore: a cross sectional study. International Journal of Science \& Healthcare Research. 2021; 6(3): 193-196. DOI: https:// doi.org/10.52403/ijshr.20210732 